\title{
Responsabilidade penal no transtorno bipolar
}

\author{
Penal responsibility in bipolar disorder \\ Alexandre Martins Valença', Antonio Egidio Nardi²
}

\section{RESUMO}

\section{Palavras-chave}

Transtorno do humor, violência, crime, psiquiatria forense.

\begin{abstract}
Os autores relatam o caso de uma mulher que cometeu delito de assalto e foi avaliada em perícia psiquiátrica para análise da responsabilidade penal. Conclui-se que ela apresentava doença mental, na forma de transtorno bipolar, daí ser inimputável. A avaliação da responsabilidade penal é de extrema importância, para que se possam aplicar medidas de segurança ou sanções penais e correcionais adequadas a cada caso.
\end{abstract}

\section{Keywords}

Mood disorder, violence, crime, forensic psychiatry.

\begin{abstract}
The authors report a case of a woman who committed the crime of assault and was evaluated in penal imputability exam to assess criminal responsibility. It was concluded that she had a mental illness, bipolar disorder, being inimputable. The evaluation of penal responsibility is extremely important, in order to apply adequate involuntary commitment or correctional and penal sanctions to each case.
\end{abstract}

\section{INTRODUÇÃO}

Em Direito Penal, para que alguém seja responsável penalmente por determinado delito, são necessárias três condições básicas: ter praticado o delito, na época do delito ter entendimento do caráter criminoso da ação e ter sido livre para escolher entre praticar e não praticar'.

O Código Penal (CP) brasileiro² (Lei Substantiva Penal), em seu Título III (Da Imputabilidade Penal), trata dos casos de inimputabilidade, ou seja, daqueles que, embora tenham cometido um crime, não podem ser responsáveis por ele ou o são parcialmente, tendo, destarte, suma imputabilidade abolida, no primeiro caso, ou diminuída, no segundo. Além dos menores, que recebem outro tratamento jurídico em legislação especial, a lei declara isentos de pena, sob certas condições, aqueles que cometem ação ou omissão e apre- sentam transtornos mentais. Ela prevê, ainda, também sob certas condições especiais, a redução da pena respectiva para algumas formas de transtorno mental ${ }^{3}$.

Do ponto de vista jurídico, a responsabilidade pressupõe no agente, contemporaneamente à ação ou omissão, a capacidade de entender o caráter criminoso do fato e a capacidade de determinar-se de acordo com esse entendimento. É possível, então, definir a responsabilidade como a existência dos pressupostos psíquicos pelos quais alguém é chamado a responder penalmente pelo crime que praticou. Nesse aspecto, dois conceitos importantes são o de responsabilidade e imputabilidade, significando essa a condição psíquica da punibilidade, enquanto aquela designaria a obrigação de responder penalmente ou de sofrer a pena por um fato determinado, pressuposta a imputabilidade. De acordo com Vargas ${ }^{4}$ o conceito básico de imputabilidade seria a condi-

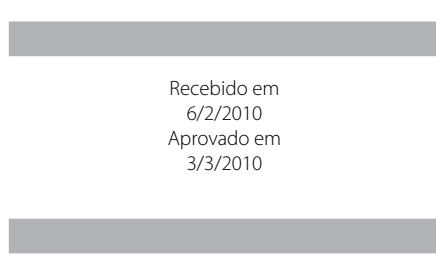

1 Universidade Federal Fluminense (UFF), Departamento de Psiquiatria e Saúde. 2 Universidade Federal do Rio de Janeiro (UFRJ), Instituto de Psiquiatria.

Endereço para correspondência: Alexandre Martins Valença Departamento de Psiquiatria e Saúde Mental, UFF Rua Marquês do Paraná, 303, 30 andar (prédio anexo ao HUAP) - 24030-210 - Niterói, RJ E-mail:avalen@uol.com.br 
ção de quem tem aptidão para realizar com pleno discernimento um ato. Representa a imputabilidade uma relação de causalidade psíquica entre o fato e o seu autor. Com uma frase interessante, Von Liszt, apud Lutz ${ }^{5}$, resume bem essa questão: "imputável é todo indivíduo mentalmente desenvolvido e mentalmente são".

Ao cometer um delito, um indivíduo considerado responsável será submetido a uma pena. Ao inimputável será aplicada uma medida de segurança. Cabe ao perito informar se o indivíduo é mentalmente desenvolvido e mentalmente são. Ao juiz compete sentenciar sobre a capacidade e responsabilidade (aplicação de pena ou medida de segurança). Quanto à aplicação da medida de segurança, a lei presume a periculosidade dos inimputáveis, determinando a aplicação da medida de segurança àquele que cometeu o ilícito e se apresenta nas condições do artigo 26. Essas disposições estão presentes no artigo 26 do Código Penal2, em seu caput e parágrafo único.

Na fixação do pressuposto da responsabilidade penal baseado na culpa moral, o critério utilizado pelo Código Penal brasileiro é o biopsicológico ou misto. A responsabilidade só é excluída se o agente, em razão de doença mental ou retardamento mental, era, no momento da ação, incapaz de entendimento ético-jurídico e autodeterminação.

\section{RELATO DE CASO}

M, 30 anos, sexo feminino, brasileira, natural e residente do Rio de Janeiro, amasiada, ensino superior incompleto, professora de Ensino Médio. Consta na denúncia descrita nos autos do processo criminal que $\mathrm{M}$ foi acusada de tentar assaltar um estabelecimento comercial, na cidade de São Paulo, ameaçando funcionários com um canivete, dessa forma sendo enquadrada no artigo 157 do Código Penal ${ }^{2}$ (subtrair coisa móvel alheia, mediante grave ameaça ou violência).

Em sua versão dos fatos, durante a avaliação pericial, afirmou: "Eu peguei um ônibus e fui para São Paulo, fui a esmo, sem objetivo, achava que tinha que fazer alguma coisa em São Paulo, aí, fiquei andando pelo aeroporto e gastei todo meu dinheiro. Fiquei desesperada para voltar para casa, aí eu fui numa pizzaria e falei para o cara me dar o dinheiro que tava no caixa se ele tivesse amor à vida. Depois entrei no banheiro e me pegaram".

Negou passado de traumatismo cranioencefálico, de crises convulsivas ou de uso de álcool ou substâncias psicoativas. Relata que o pai "tinha crise de agitação e foi internado várias vezes". Referiu passado de tratamento psiquiátrico contando com internações psiquiátricas anteriores em hospitais públicos na cidade do Rio de Janeiro: "ficava com um alto astral, agitada, falando muito, sem dormir". Há referência também a episódios depressivos "sem comer e sem falar nada, pensando em morrer". Afirma que na época do delito "estava há dias sem dormir, muito agitada, só pensando em baladas". Atualmente faz tratamento psiquiátrico ambulatorial, em uso de lítio. Traz receita médica.

$\mathrm{Na}$ avaliação psiquiátrica pericial, M compareceu ao local de exame trajada adequadamente para a ocasião, com maquiagem excessiva, em boas condições de higiene. Tinha atitude colaborativa, respondendo aos dados que lhe eram formulados, porém se irritando com o entrevistador, quando ele tentava detalhar algum aspecto daquilo que relatava. Falava de forma rápida e ininterrupta, apresentava inquietação motora, gesticulando de forma excessiva e levantando da cadeira da sala em várias ocasiões, durante a realização da entrevista. Apresentava consciência vigil, atenção dispersa, globalmente orientada, memórias preservadas para fatos recentes e remotos. Não apresentava sintomatologia delirante ou alucinatória em curso. Apresentava inteligência dentro dos limites de normalidade e humor exaltado e irritado. Sua autocrítica era pobre em relação ao delito de que era acusada: "eu queria pegar um lanche porque tava com fome, não fiz nada demais".

Na conclusão do laudo, foi considerado que na época dos fatos M apresentava doença mental compatível com diagnóstico de transtorno afetivo bipolar (F31-CID-106). Esse diagnóstico se fez presente pela existência de episódios de excitação psíquica e depressão. Eles motivaram diversas internações psiquiátricas, denotando a gravidade de suas manifestações na conduta da pericianda. Nos episódios de excitação, M apresentava logorreia, hiperatividade, desinibição comportamental, exaltação do humor, heteroagressividade e agitação psicomotora. Esses sintomas, por sua vez, afetaram inteiramente o seu entendimento e determinação em relação à licitude dos atos praticados na denúncia, dessa forma sendo considerada inimputável.

\section{DISCUSSÃO}

Em um episódio maníaco, tanto o pensamento (momento cognitivo) quanto o comportamento e volição (momento cognitivo) apresentam-se muito alterados, por causa de uma aceleração de todos os processos psíquicos, na presença de distúrbios psicopatológicos da afetividade e vontade, afetando inteiramente o entendimento e a determinação do indivíduo, daí a inimputabilidade, como no caso em questão. É importante salientar que a hipomania e a depressão moderada podem trazer prejuízo na capacidade de entendimento e determinação, o que pode apontar para a semi-imputabilidade (parágrafo único do artigo 26 do (P²).

O método biopsicológico exige a averiguação da efetiva existência de um nexo de causalidade entre o estado mental anômalo e o crime praticado, isto é, que esse estado, contemporâneo à conduta, tenha privado parcial ou completa- 
mente o agente de qualquer das mencionadas capacidades psicológicas (seja a intelectiva ou a volitiva). É indispensável o exame psiquiátrico pericial sempre que houver dúvidas em relação à sanidade mental do acusado. Entretanto, cabe ao juiz a palavra final na decisão de aplicar pena ou medida de segurança. A conclusão positiva do laudo pericial não substitui a sentença judicial, que é soberana. É importante salientar que a avaliação pericial será de natureza retrospectiva, procurando identificar o funcionamento mental do autor do crime no momento em que esse crime ocorreu.

Diversos estudos têm fornecido evidência de que o risco de comportamento violento pode ser elevado entre os pacientes com transtornos afetivos ${ }^{7-10}$. Entretanto, o risco de violência associado ao transtorno bipolar não tem sido separado daquele associado à depressão psicótica, em muitos estudos, frequentemente por limitações do tamanho das amostras. O risco de violência no transtorno bipolar é maior na fase maníaca do que na depressiva ${ }^{11}$. Recentemente, houve oportunidade de descrever um caso de matricídio de muIher com transtorno bipolar, submetida à perícia psiquiátrica, também considerada inimputável ${ }^{12}$.

Dean et al..$^{13}$ investigaram parte dos dados de um estudo denominado Etiologia e Etnicidade na Esquizofrenia e Outras Psicoses (AESOP), um estudo de base populacional de dois anos, em dois centros da Inglaterra. A amostra foi constituída por 495 pacientes. Desses, 194 (39,2\%) foram agressivos em sua primeira apresentação em serviços de atendimento, sendo também o comportamento agressivo o principal motivo da presença nesses serviços. Os pacientes que se apresentaram aos serviços com comportamento agressivo tiveram mais diagnóstico de esquizofrenia e mania do que de depressão psicótica.

Ainda de acordo com esse último estudo, um diagnóstico de mania foi significativamente mais comum do que de esquizofrenia no grupo agressivo, comparado ao não agressivo. Os pacientes agressivos tiveram quatro vezes mais histórico de comportamento violento prévio, além de mais histórico de abuso de drogas no ano anterior, especialmente cannabis sativa e anfetamina. Outro achado foi que os sintomas associados à agressão foram aqueles tipicamente encontrados na mania: senso de funcionamento subjetivo aumentado, humor expansivo, ideias delirantes de grandeza e hiperatividade. Outro achado foi que os pacientes com diagnóstico de mania foram três vezes mais agressivos no primeiro contato do que os pacientes com esquizofrenia.

\section{CONCLUSÃO}

O laudo psiquiátrico-forense representa a contribuição do conhecimento psiquiátrico para o esclarecimento de um fato de interesse jurídico e contém o raciocínio e a contribuição do perito. Esse vai fundamentar o diagnóstico psiquiátrico, com base nas principais alterações psicopatológicas apontadas no exame mental, avaliar a influência da doença mental na capacidade de entendimento e determinação na época do delito e, finalmente, estabelecer se há um nexo de causalidade entre a doença e o delito cometido, de acordo com o critério biopsicológico.

O estudo da responsabilidade penal de indivíduos com transtornos mentais é de interesse para a justiça criminal, para a psiquiatria e a sociedade como um todo. A avaliação da responsabilidade penal é de extrema importância, para que se possa ajustar em cada caso a aplicação de medidas de segurança e de sanções penais e correcionais adequadas.

\section{REFERÊNCIAS}

1. Palomba GA. Tratado de psiquiatria forense. São Paulo: Atheneu; 2003.

2. Código de Processo Penal. 3. ed. São Paulo: Ed. Revista dos Tribunais; 1998.

3. Chalub M. Perícias de responsabilidade penal e de dependência química. In: Taborda JGV, Chalub M, Abdala-Filho E, editores. Psiquiatria forense. Porto Alegre: Artmed; 2004.

4. Vargas HS. Manual de psiquiatria forense. 1. ed. Rio de Janeiro: Livraria Freitas Bastos S.A.; 1990.

5. Lutz GA. A responsabilidade criminal no novo Código Penal. Rio de Janeiro: Arquivos do Manicômio Judiciário; 1941. p. 78-131.

6. Classificações de transtornos mentais e de comportamento da CID-10. Porto Alegre: Artes Médicas; 1993

7. Hodgins S, Mednick SA, Brenann PA, Schulsinger F, Engberg M. Mental disorder and crime. Evidence from a Danish birth cohort. Arch Gen Psychiatry. 1996;53(6):489-96.

8. Brennan PA, Mednick SA, Hodgins S. Major mental disorders and criminal violence in a Danish birth cohort. Arch Gen Psychiatry. 2000;57(5):494-500.

9. McNeil DE, Binder RL, Greenfield TK. Predictors of violence in civilly committed acute psychiatric patients. Am J Psychiatry. 1988;145:965-70.

10. Tiihonen J, Isohanni M, Rasanen P, Koiranen M, Moring J. Specific major mental disorders and criminality: a 26-year prospective study of the 1996 Northern Finland birth cohort. Am J Psychiatry. 1997;154(6):840-5

11. Yesavage JA. Bipolar illness. Correlates of dangerous inpatient behavior. Br J Psychiatry. 1983;143:554-7.

12. Valença AM, Mezzasalma MA, Nascimento I, Nardi AE. Matricídio e transtorno bipolar. Rev Psiq Clin. 2009;36(4):163-7.

13. Dean K, Walsh E, Morgan C, Demjaha A, Dazzan P, Morgan K, et al. Aggressive behavior at first contact with services: findings from the AESOP First Episode Psychosis Study. Psychol Med. 2007;37:547-57. 